\title{
Fatigue Flexural Behavior of RC Beams Strengthened using GFRP-Sheet After Seawater Immersion
}

\author{
Arbain Tata ${ }^{1}$ \\ Civil Engineering Department \\ Khairun University \\ Ternate, Indonesia \\ 1'arbatata@yahoo.co.id \\ Anthonius Frederik Raffel \\ Architect Engineering Department \\ Khairun University \\ Ternate, Indonesia
}

\author{
Muhammad Ihsan \\ Civil Engineering Department \\ Sekolah Tinggi Teknik Baramuli \\ Pinrang, Indonesia \\ Rudy Djamaluddin \\ Civil Engineering Department \\ Hasanuddin University \\ Makassar, Indonesia
}

\begin{abstract}
Bridges or docks on coasts often fail due to fatigue loads. Sea waves striking bridge or the dock give a fatigue effect to the structure thus accelerating structural failure. This study aims to analyse glass fibre reinforced polymer (GFRP) reinforcement on reinforced concrete beams under fatigue and monotonic loads influenced by sea water. One normal concrete flexural beam (BN) with repetitive load was without seawater and no reinforcement. One flexural beam was without seawater immersion but with GFRP-reinforcement. Another flexural beam reinforced by GFRP sheets is immersed in a pond containing seawater with time variations up to twelve months. The results showed an increase in capacity due to GFRP-reinforcement. There is a decrease in the capacity of GFRP sheet influenced by seawater immersion. The same trend with the decrease in ductility occurred in the flexural beam to seawater immersion. The failure occurring in the flexural beam was preceded by the failure of the attachment between the concrete and the GFRP sheet at the load centre (mid of span) slowly to the support until failure (debonding) initialized. The GFRP-S bonding capacity to the concrete skin has decreased in twelve months. Therefore, there is a significant effect of decreasing strength due to seawater immersion.
\end{abstract}

Keywords_fatigue loads; flexural beam; GFRP sheet; seawater immersion

\section{INTRODUCTION}

The application of fiber reinforced polymer (FRP) materials as an option the enhancement of structural integrity has gained popularity in recent years. Carbon fiber reinforced polymers (CFRP) as a type of FRP materials have been widely applied in retrofitting building and bridge structure and have been proven capable and effective in improving capacity to withstand static load of concrete beam as well as its durability [1][2]. Effects of overloading to increasing fatigue of internally bond carbon fiber (CFRP) lamination and the mechanism underlying the accumulation of fatigue deterioration of bridge girder strengthened by CFRP under overloading condition have been investigated through experimental study of static and fatigue behaviour of small-scale reinforced concrete girders [3].
One advantage of GFRP material is its lightweight property thus it would not contribute additional weight to the structure [2][4]. Other advantages such as high tensile stress and corrosion resistance give contribution to its wide application, as well as its rather simplicity when compared to conventional concrete. It is also considered environmentally friendly. Many research efforts have been conducted and applied particularly in the improvement of the capacity of the flexural beam as a respond to the increase of load requirements, usage alteration, degradation of the structure, and complexity in design as well as construction defects [5-8]. Another research is the investigation on the efficiency of reinforcement with CFRP on corroded girders as indicated by an increase in fatigue life of reinforced beams when compared to unreinforced beams [9].

Of many researchers conducted, most are discussing beams with GFRP reinforcement on the tensile side by using static loading. However, girders on bridge bear repetitive loads more than static loads. Repetitive loads are gained from passing vehicles. This type of loading is the dominant factor in the ruptures of bridge structures. Several research results have proved that influence of ruptures or failures of structure even in a less magnitude of loading far below ultimate flexural capacity [10]. Some other investigations have used Glass Fiber Reinforced Plastics (GFRP) to increase the flexural strength of beam [6]. In this regard, the innovation of durability of reinforced concrete beam strengthened by GFRP due to fatigue load is still opened to be investigated further. Therefore, in this research, GFRP Sheets were applied as reinforcement for flexural beam under fatigue and static load as well as immersion of sea water.

The increasing of the deflection on the reinforced concrete beams caused by the decreasing of the secant modulus of concrete due to creep as well as modulus of future of concrete. Creep strain in the compression zone under cyclic loading was noted as a main factor for the increased deflection of a 
reinforced concrete beams. The effective secant modulus of elasticity of concrete $E_{e, n}$ be accounted as [11].

$$
\begin{aligned}
& E_{e, N}=\frac{S_{\max }}{\frac{S_{\max }}{E_{c}}+E_{c, n}} \\
& f_{r, N}=f r\left(1-\frac{\log 10^{n}}{10,954}\right)
\end{aligned}
$$

Where $\mathrm{N}$ is the number of cycles, $\mathrm{S}_{\max }$ is the maximum compressive stress in concrete, $\mathrm{E}_{\mathrm{c}}$ is the static modulus of clarify of concrete and $\mathrm{E}_{\mathrm{c}, \mathrm{n}}$ is the cyclic creep strain in concrete which consist of a mean strain component resulting from the static mean stress and cyclic strain component which depend on stress range. where fr is the initial modulus of rupture of concrete, and $\mathrm{f}_{\mathrm{r}, \mathrm{N}}$ is the initial modulus of rupture of concrete after $\mathrm{N}$ cycles of loading. The design procedure for FRP reinforced beam in this research follows ACI 440.2R-08 Guide for the Design and Construction of Externally Bonded FRP System for Strengthening Concrete Structures". The stressstrain condition of concrete beam section is depicted in Fig. 1 illustrates the internal strain and stress distribution for a rectangular section under flexure at the ultimate limit state. The calculation procedure used to arrive at the ultimate strength should satisfy strain accountability and force equilibrium and should consider the governing mode of failure. Several calculation procedures can be derived to satisfy this condition.

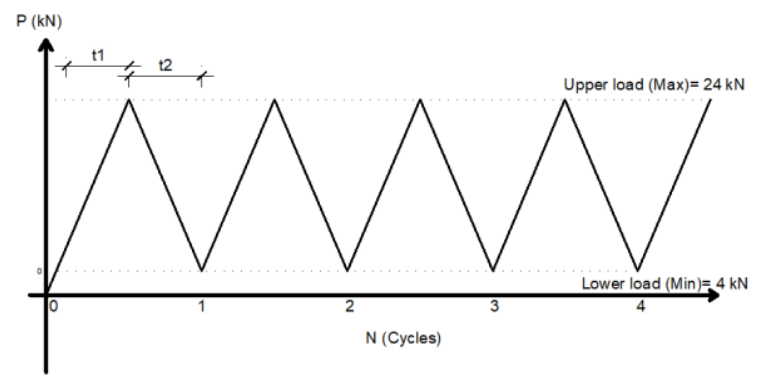

Fig. 1. Fatigue loads

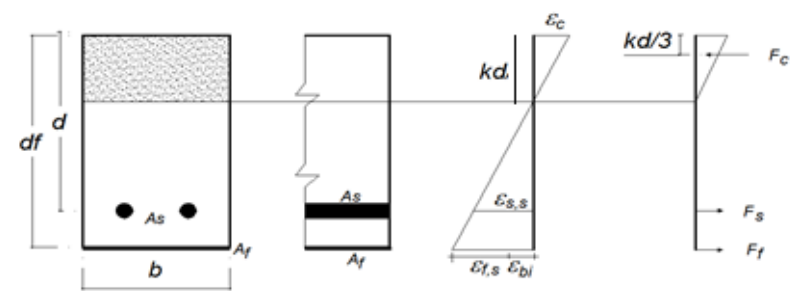
(a) Cross section
(b) Strain
(c) Stress

Fig. 2. Elastic strain and stress distribution

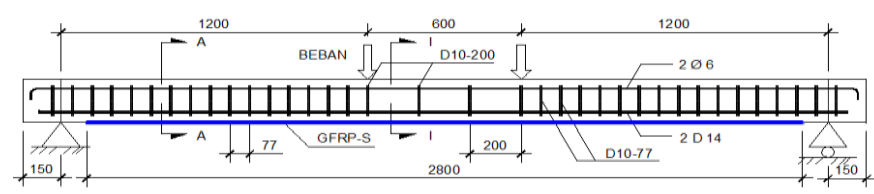

Fig. 3. Details of tested beam
Where $f_{s, s}$ is stress level in non-prestressed steel reinforcement at service loads, $f_{f, s}$ is stress level in FRP caused by a moment within elastic range of member, $E_{f}$ is service moment at section, $M_{S}$ is the tensile modulus of elasticity of GFRP-S, $E_{S}$ is the modulus of elasticity of steel.

$$
\begin{gathered}
f_{S, S}=\frac{\left[M_{s}+\varepsilon_{b i} A_{f} E_{f}\left(d_{f}-\frac{k d}{3}\right)\right](d-k d) E_{s}}{A_{s} E_{S}\left(d-\frac{k d}{3}\right)(d-k d)+A_{f} E_{f}\left(f-\frac{k d}{3}\right)\left(d_{f}-\frac{k d}{3}\right)} \\
f_{f, s}=f_{S, S}\left(\frac{E_{f}}{E_{s}}\right) \\
M_{S}=f_{S, S}
\end{gathered}
$$

\section{MATERIAL AND SPECIMENS}

\section{A. Material}

Type of concrete type employed in the research was normal concrete with a design the compressive strength of $25 \mathrm{MPa}$. The compressive and flexural strength of concrete were examined through cylindrical compressive strength test and flexural beam test. The concrete casting was conducted in compliance with the standard. Concrete formwork dismantling was conducted on day three followed by curing which was conducted by covering the specimens with a wet sack for 28 days. All reinforced concrete beam specimens were designed by design standard [8]. Figure 3 shows the details of the prepared test beam. The concrete beam was prepared in the cross-sectional dimension of $100 \mathrm{~mm} \times 120 \mathrm{~mm}$ with 3,300 mm length.

The beam is designed with 2D14 steel bar as a tensile reinforcement. From the tensile D14 steel bar test, it was obtained average yield stress of 421,7 MPa, while D10 stirrup steel bar, yield stress is indicated an average of 410,2 MPa. Steel tensile test data of month 1 and month 2 show no significant difference. The results have complied design yield stress level of $400 \mathrm{MPa}$.

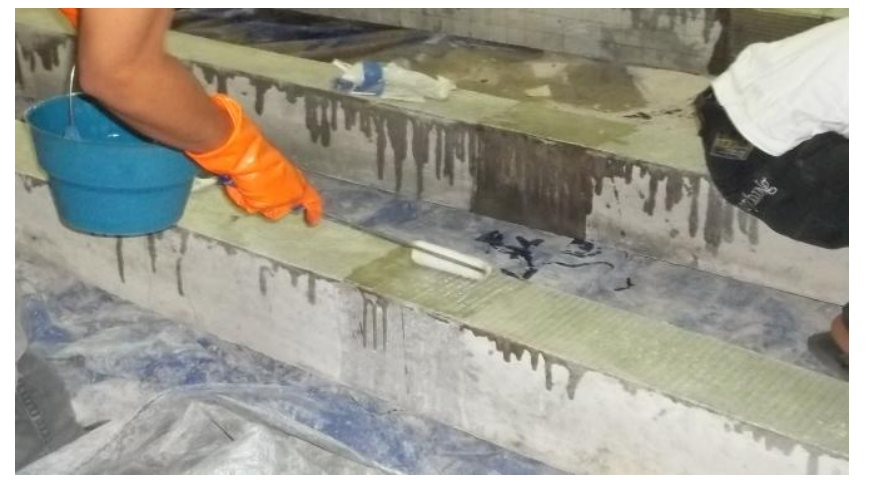

Fig. 4. Applied GFRP sheet 


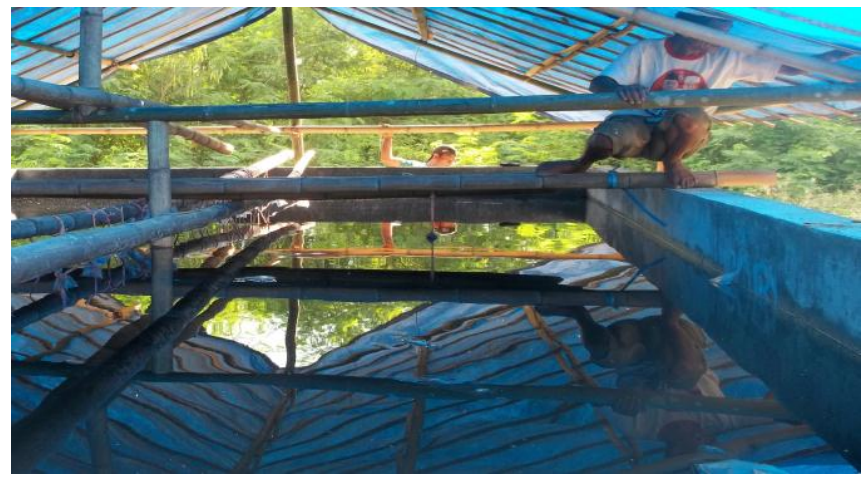

Fig. 5. Seawater immersion pool

To prevent from sliding failure, reinforcement bar with a diameter of $6 \mathrm{~mm}$ is used as stirrups. FRP materials used are glass fiber reinforced polymer-sheet (GFRP-S). The combination of glass fiber and epoxy resin would develop GFRP-S reinforcement on concrete beams. Application of GFRP-S as beam's reinforcement was conducted after beams had reached 28 days.

The application process for strengthening the beam is on procedures by the standard as shown in Fig. 4. Initially, the surface of beam at the tensile side was cleaned by polishing its surface. The glass fiber sheet was then cut out according to the desired size and coated with an epoxy resin. Then, the glass fiber sheet was affixed into the surface of concrete after the surface had been coated with an epoxy resin as well. After properly positioned, the sheet material was then sealed off and coated with epoxy resin using a roller that the entire sheet became saturated with epoxy material. Further, the test material was left dry to make the epoxy resin material harden and fused with glass fiber material to form the GFRP-S attached to the tensile side (bottom side) of the reinforced concrete beam.

The simulation pool made has a dimension of $8.30 \mathrm{~m}$ in length and $4.30 \mathrm{~m}$ in width and $1.15 \mathrm{~m}$ in height. The dimensions of the pond are adjusted to the size of the flexible beam to be studied. The detailed picture of the simulation pool can be seen in Fig 5 .

The specification of Glass fiber reinforcement polymer (GFRP-S) is designed to meet type SHE-51A with material properties such as tensile stress of $3.24 \mathrm{GPa}$ and tensile modulus of $72.40 \mathrm{GPa}$. The material also has maximum strain to $4.5 \%$. The density and thickness of GFRP-S are designed on 2.55 $\mathrm{gr} / \mathrm{cm} 3$ and $0.36 \mathrm{~mm}$ respectively. The properties of epoxy resin are determined by the tensile stress, young modulus dan bonding stress with the values of $72.4 \mathrm{MPa}$ for tensile stress, $3.18 \mathrm{GPa}$ for young modulus and 2.12 $\mathrm{MPa}$ for bonding stress.

\section{B. Specimens}

Application Fatigue load was tested with fatigue testing instrument with a loading capacity of 100 ton. As shown in Fig. 4 , before the testing, strain gauges were affixed into the surface of concrete and surface of GFPR-S to measure the strain in the test specimen during the loading process. Specimen beam was placed on top of two simple supports which behave as hinge- roll. The load is given into two points at $50 \mathrm{~cm}$ distance at the middle of beam's span. The magnitude of load amount is given through measured by using Load-Cell while the deflection is measured by using LDVT which is placed at the midpoint of beam's span. All measurement instruments are connected into a data tabulation system and connected to the computer to monitor all measured parameters during the loading process. The beam is designed to be loaded by fatigue load with minimum load $4 \mathrm{kN}$ (or around $5 \%$ from the ultimate flexural capacity) and maximum load $24 \mathrm{kN}$ (or around $45 \%$ from ultimate compressive strain of concrete). The minimummaximum load pattern was given repeatedly with frequency $1.25 \mathrm{~Hz}$ and was given continuously until specimen failure. The data reading was conducted after the beam experiencing repetitive load with a period of 10 cycles, 100 cycles and multiples of 50,000 cycles until beam failure.

Next fatigue tests were conducted when the test beam has been immersed in seawater for $1,3,6$ and 12 months. Deflection is also measured by using LDVT on the lower part of the beam. Crack patterns were also investigated by using phi gauge. Loading was conducted by the two-point loads on BN and BF. Fatigue load could cause fatigue and failure, with a constant frequency of $1.25 \mathrm{~Hz}$ and sine wave model load as depicted in Fig. 6. Sinusoidal fatigue loads were applied in 1 cycle, 10 cycles, 100 cycles, 1000 cycles, 10,000 cycles and subsequent multiplies of 50,000 cycles until beam failure or until reaching $1,000,000$ cycles. Loading was given in minimum and maximum for a respective beam of unreinforced type (BN), and GFRP-S reinforced one (BF) with magnitudes of $4 \mathrm{kN}-19 \mathrm{kN}$ and $4 \mathrm{kN}-24 \mathrm{kN}$. Minimum load is estimated from a dead load of the beam while maximum loads of $19 \mathrm{kN}$ or $24 \mathrm{kN}$ are estimated from $45 \% \mathrm{f}$ 'c of control beam of the respective type of beam, GFRP-S reinforced and unreinforced.

TABLE I. SUMMARY OF THE SPECIMENS

\begin{tabular}{|c|c|c|c|}
\hline No & $\begin{array}{c}\text { Test object code } \\
\text { (fatigue load) }\end{array}$ & $\begin{array}{c}\text { Number of test } \\
\text { objects }\end{array}$ & $\begin{array}{c}\text { Loading } \\
\text { system }\end{array}$ \\
\hline 1 & BNS & 2 & Monotonic \\
\hline 2 & BFS & 2 & Monotonic \\
\hline 3 & BN & 2 & Fatigue \\
\hline 4 & BF0 & 2 & Fatigue \\
\hline 5 & BF1 & 2 & Fatigue \\
\hline 6 & BF3 & 2 & Fatigue \\
\hline 7 & BF6 & 2 & Fatigue \\
\hline 8 & BF12 & 2 & Fatigue \\
\hline
\end{tabular}

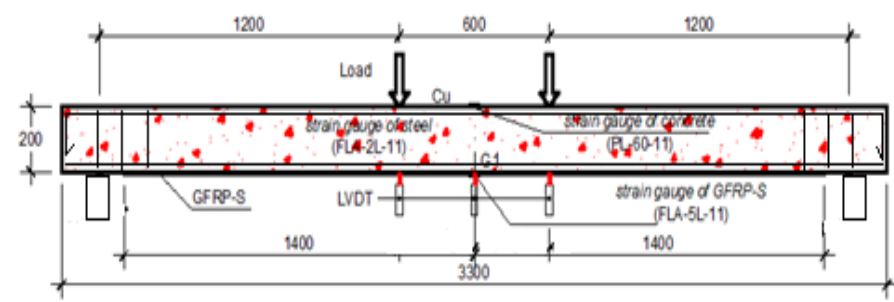

Fig. 6. Record Data 


\section{TESTING METHOD}

Fatigue load was tested with fatigue testing instrument as shown on Fig. 1d with loading capacity of 100 ton. Before the testing, strain gauges were affixed into the surface of concrete and surface of GFPR-S to measure the strain in the test specimen during loading process. Specimen beam was placed on top of two simple supports functioned as placement system of joint. Load is given into two points at $50 \mathrm{~cm}$ distance at the middle of beam's span. Magnitude of load amount is given through measured by using Load-Cell while the deflection is measured by using LDVT which is placed at the midpoint of beam's span. All measurement instruments are connected into data tabulation system and connected to the computer to monitor all measured parameters during the loading process. Beam is designed to be loaded by fatigue sin wave with minimum load $4 \mathrm{kN}$ (or around $5 \%$ from ultimate flexural capacity) and maximum load $24 \mathrm{kN}$ (or around $45 \%$ from ultimate compressive strain of concrete). The minimummaximum load pattern was given repeatedly with frequency $1.5 \mathrm{~Hz}$ continuously until specimen failure. The data reading was conducted after the beam experiencing repetitive load with period of 10 cycles, 100 cycles and multiples of 50,000 cycles until beam failure. Determination of maximum-minimum load is based on the test result from static load which obtained from the observations of relationship between load and strain occurring at the side of maximum compressive side of concrete.

\section{RESUlT AND DISCUSION}

Before discussion of the behaviour of the beam due to fatigue load, the discussion will be then on the behaviour of control beam due to monotonic load. This is conducted to evaluate the influence of fatigue loads when compared with the influence of monotonic load. The stiffness of the structure is important. Stiffness restriction is used to keep the structure from over deflection. Stiffness is defined as the force required to produce a unit of displacement. The value of stiffness is the gradient of the relationship between load and deflection. The stiffness of a concrete beam is a function of the elastic modulus (E) and the moment of inertia (I).

In this research, there are four pieces of test beam loaded with monotonic load until the beam is cracked and destroyed immediately as the load increases. The four tested beams are: BNK1, BNK2, BFK1 and BFK2 which can be seen in Fig. 7

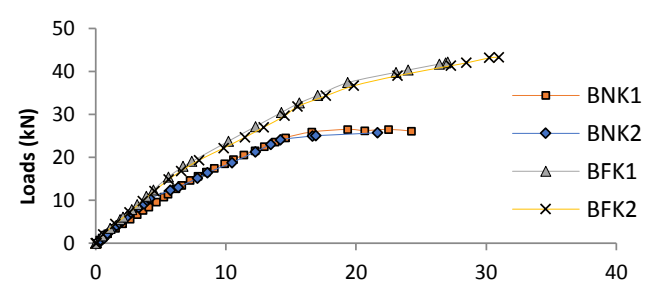

Fig. 7. Relationship of load to deflections of concrete beam BNK1, BNK2, $\mathrm{BFK} 1$ and BFK2

Figure 7 depicts beam deflection behaviour for BNK1, BNK2, BFK1 and BFK2. From the graph, it can be explained that the behaviour of each specimen is by the characteristics of each beam. For BNK1 beam, the loaded relationship at the beginning of loading is still a linear line showing full elastic behaviour up to $5.07 \mathrm{kN}$ loading with a deflection of $2.07 \mathrm{~mm}$. As the load increases, the reinforcing steel bar yields with a noticeably larger deflection without being followed by an increase in load with a load value of $22.90 \mathrm{kN}$ and a deflection of $14.57 \mathrm{~mm}$ where the nonlinear load relation curve to deflection becomes much flatter than before. This occurred until the beam reaches a maximum load of $26.44 \mathrm{kN}$ and deflection of $36.07 \mathrm{~mm}$. As for BNK2 test specimen, the trend is still linear at the beginning of loading showing full elastic behaviour before reaching $5.07 \mathrm{kN}$ load with a $1.62 \mathrm{~mm}$ deflection. As the load increased, the reinforcing steel bar started to yield which is marked by a large increase of deflection without a significant load increase where the load value is 24.10 $\mathrm{kN}$ with a deflection of $14.21 \mathrm{~mm}$, the nonlinear relationship curve is much flatter than before. This occurs until the beam reaches a maximum load of $24.10 \mathrm{kN}$ and a deflection of 21.67 $\mathrm{mm}$.

Normal beam $(\mathrm{BN})$ failed at 835,000 cycles. On minimum load level $(\mathrm{P}=4 \mathrm{kN})$, the deflection was still unnoticeable after fatigue loading. However, at the higher load level, the change of deflection is quite significant. On maximum load (19 kN), fatigue load influence increases to $11.03 \%$ after the beam experiencing 800,000 cycles of fatigue load.

What occurred to normal beam without reinforcement also occurred in reinforced concrete beams strengthened with GFRP-S. Figure 8 shows deflections on GFRP-S strengthened beams for various loading levels after undergoing fatigue loads up to $1,230,000$ cycles. The average numbers of cycles, when GFRP-S strengthened beams experienced failure, were $1,000,000$ cycles. At the relatively small load level $(\mathrm{P}=4 \mathrm{kN})$ the deflection appears not to be influenced by the fatigue load. At higher load levels the effect of repeated loading has begun to appear. At $14 \mathrm{kN}$ load, there is an increase in deflection after the beam underwent $1,000,000$ cycles of fatigue loading. At 24 $\mathrm{kN}$ load, the influence of fatigue load is increasingly visible where deflection increased after in loaded 1,000,000 cycles. The effect of fatigue loading after 1,200,000 cycles for different levels of loading tends to decrease as immersion proceeded. This can be indicated by the weakening of the GFRP-S bond to the concrete on the tensile side. In general, structural weakness is also caused by the fatigue load caused by the emergence of micro cracks due to repetitive loads.

Figure 9 shows compressive strain occurring on the compressed side of the GFRP-S reinforced beam for various loading levels after fatigue load cycles up to 1,000,000 cycles. At BF-0 (before immersed), there is an increase in the compressive strain as some cycles increases from the first cycle to one million cycles at a maximum load of $24 \mathrm{kN}$ with a concrete compressive strain of $716 \mu$ to $795 \mu$. This shows an increase of compressive strain by $11 \%$ due to a fatigue load of a million cycles. As for BF-12 (12-month immersion), there was an increase in compressive strain as some cycles increases from the first cycle to one million cycles at a maximum load of $24 \mathrm{kN}$ with a concrete compressive strain of $1,308 \mu$ to $1,794 \mu$. This 
shows an increase of $37 \%$ compressive strain due to a fatigue load of one million cycles. These results indicate that there is an effect of increasing the compressive strain of $26 \%$ due to seawater immersion and indicated by the weakening of concrete bonds to GFRP due to seawater immersion or slow crack propagation processes due to repetitive loads.

As shown in Fig. 10, at higher load levels, it appears that the effect of repetitive loading appears were more significant. In contrast to reinforcing steel, at BF-12 the $24 \mathrm{kN}$ (maximum load), the effect of fatigue load appears to be increasingly visible where strain increases after fatigue loads of one million cycles. In the GFRP-S reinforced beam for varying degrees of immersion after undergoing fatigue loading up to one million cycles, at each load level, it shows increasing strain of reinforcing steel. This indicated a decline in the capacity of bending moments due to the weakening of GFRP-S bonds to the concrete surface due to seawater immersion. At BF0, maximum load was $1044 \mu$, while on BF12, the strain was 1308 $\mu$ in the first cycle. There was a $25 \%$ increase in strain due to seawater immersion. Due to the fatigue load on the BF12, strain on the first cycle was $1308 \mu$ and was $1794 \mu$ when loaded for one million cycles $(1,000,000$ cycles $)$, while strain increases to $37 \%$.

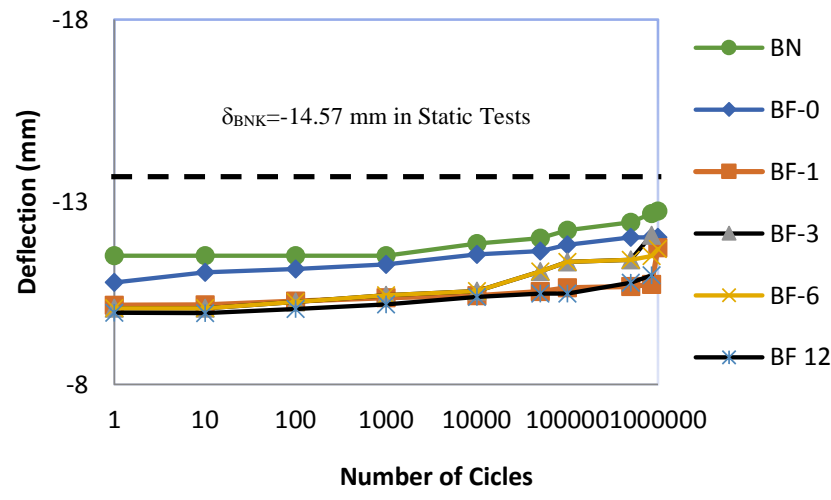

Fig. 8. Relationship of number of cycle and deflection on BN, BF0, BF1, BF3, BF6 and BF12 under maximum load in the mid of span

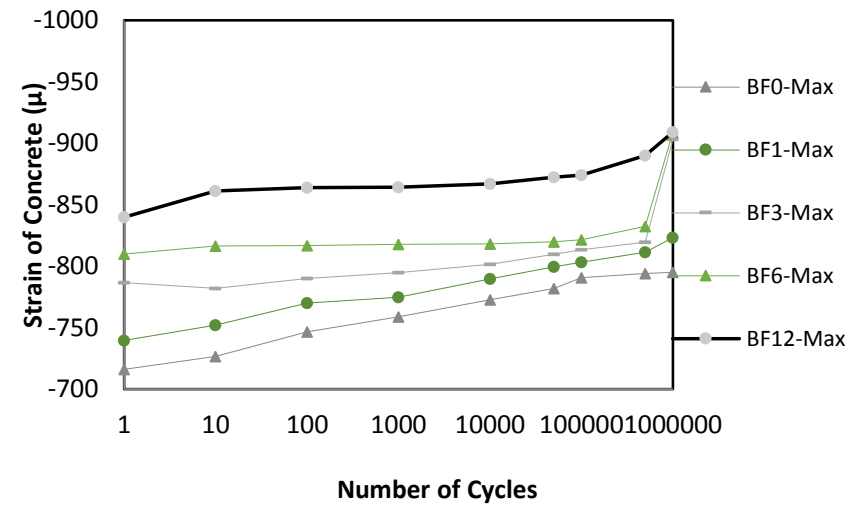

Fig. 9. Relation of concrete strain with a number of cycles for BF0, BF1, BF3, BF6 dan BF12.
The effect of the fatigue load on the GFRP-S strain is shown in Figure 11. The results show that at the relatively small load level $(\mathrm{P}=4 \mathrm{kN})$ the strain does not change after the fatigue load. However, at higher load levels it appears that the effects of recurrent loading have begun to appear. At $24 \mathrm{kN}$ loading, the influence of fatigue load tends to be more visible where the GFRP-S strain decreases after fatigue loads of one million cycles. This is an indication of weakening composite action of concrete, steel and GFRP-S. It appears that the weakening of GFRP-S action indicates a weakening of the GFRP-S bonding to the concrete surface.

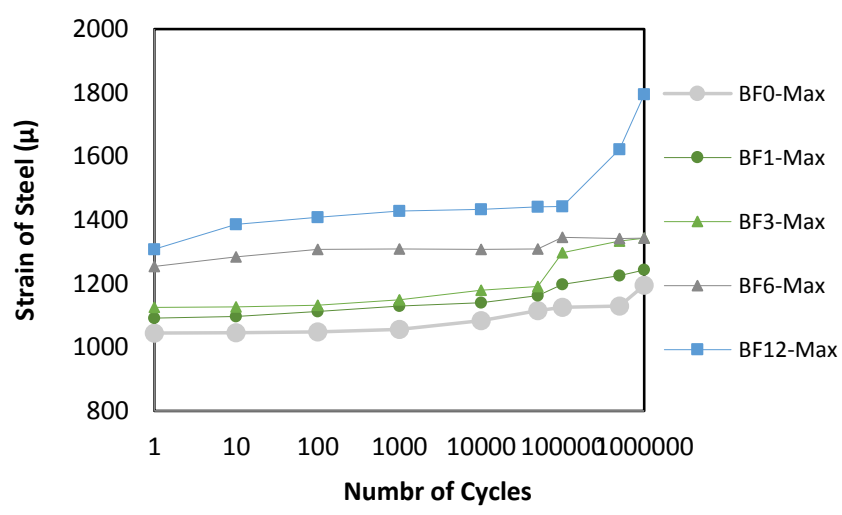

Fig. 10. Relation of reinforcing steel strain with a number of cycles for BF0, $\mathrm{BF} 1, \mathrm{BF} 3, \mathrm{BF} 6$ and BF12.

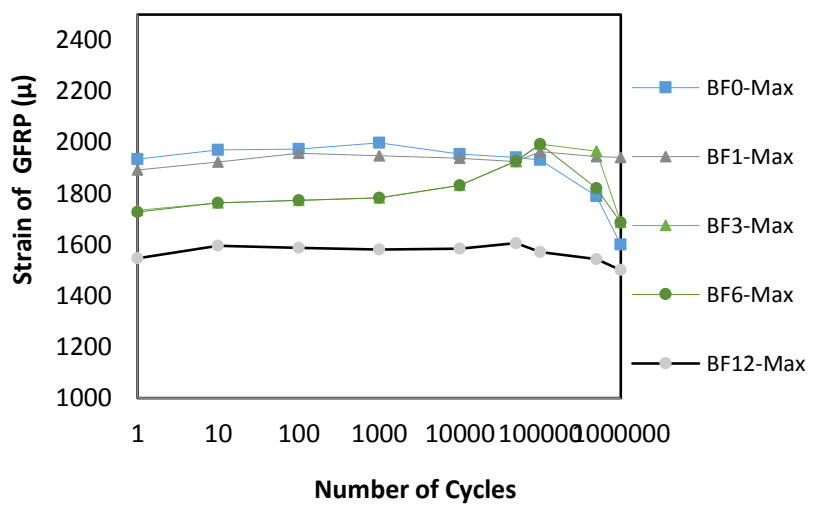

Fig. 11. Relationship of GFRP-S strain with a number of cycles for BF0, BF1, BF3, BF6 and BF12.

Table II shows fatigue life of $\mathrm{BN}$ which is significantly lower than that of $\mathrm{BF}$ where $35 \%$ increasing of fatigue life is resulted as a product of GFRP-S application. Material strains are increasing significantly. It is shown that composite actions have occurred in this regard. However, due to considerable number of parameters as well as the limitation of data reading, the accuracy of data is probably not maximized.

Figure 13. indicated an exponential trend in determining the decreasing of flexural moment of beams. It is also indicated that the decreasing of flexural moment is affected by at least 4 (four) factors of properties; concrete, GFRP-S, steel reinforcing bar and epoxy resin. The composite actions of materials have 
played very important role in determining the magnitude of beam's moment capacity in withstanding fatigue loading and immersion condition which are influential in the decreasing of strength of beam over time. It is also the reason of testing the immersed beam with static and fatigue loading.

The test beams were designed to fail with an underreinforcement failure pattern. Failure will start with a steel yield which then ended with a concrete rupture on the compressive side. Based on the static test on the beam, the maximum load for the normal beam is $24 \mathrm{kN}$ and the maximum load for the beam with GFRP-S reinforcement is $42 \mathrm{kN}$. In fatigue testing, the maximum load given is $19 \mathrm{kN}$ for a normal beam and the maximum load for the beam with GFRP-S is $42 \mathrm{kN}$. Although the maximum fatigue load given is only about $45 \%$ of the ultimate load, the beam underwent failure after repeated loads of 800 thousand to 1 million cycles. Figure 13 shows the condition of the beam undergoing fatigue after fatigue loading. On normal beam, failure occurred in the form of concrete breakdown on compressive side, while on the beam with GFRP-S failure was preceded by the release of GFRP-S on the tensile side of the beam and followed by the rupture of concrete on the compressive side. The GFRP-S bending moment capacity to the concrete skin has decreased in 12 months by $2.38 \%$. Fig. 12 shows there is a significant effect of decreasing strength due to seawater immersion.

TABLE II. MAXIMUM STRAIN WIDTH DUE TO FATIGUE LOADS IN 100,000 CYCLES

\begin{tabular}{|c|c|c|c|c|c|}
\hline & \multirow{2}{*}{$\begin{array}{c}\text { Number } \\
\text { Of cycles } \\
\text { to }\end{array}$} & \multicolumn{2}{|c|}{ Strain in 100,000 cycles $(\boldsymbol{\mu})$} & Bending \\
\cline { 3 - 5 } & $\begin{array}{c}\text { Moment } \\
\text { Failure } \\
\text { (Cycles) }\end{array}$ & $\begin{array}{c}\boldsymbol{\varepsilon}_{\boldsymbol{c}}(\boldsymbol{\mu}) \\
\text { Concrete }\end{array}$ & $\begin{array}{c}\boldsymbol{\varepsilon}_{\boldsymbol{f}}(\boldsymbol{\mu}) \\
\mathbf{G F R P}\end{array}$ & $\begin{array}{c}\boldsymbol{\varepsilon}_{\boldsymbol{s}}(\boldsymbol{\mu}) \\
\text { Steel }\end{array}$ & $\begin{array}{c}\text { Capasity } \\
\text { of GFRP- } \\
\mathbf{S}(\mathbf{N} / \mathbf{m m})\end{array}$ \\
\hline BN & 800,000 & 846,2 & - & 1326,1 & 1523.4 \\
\hline BF0 & $1,230,000$ & 794,2 & 1944,6 & 1342,1 & 1893.3 \\
\hline BF1 & $1,000,000$ & 811,4 & 1820,1 & 1224,8 & 1725.3 \\
\hline BF3 & $1,000,000$ & 819,5 & 1966,3 & 1334,2 & 2285.8 \\
\hline BF6 & $1,000,000$ & 832,5 & 1789,8 & 1659,0 & 1723.9 \\
\hline BF12 & 900,000 & 890,2 & 1543,2 & 1606,0 & 1779.4 \\
\hline
\end{tabular}

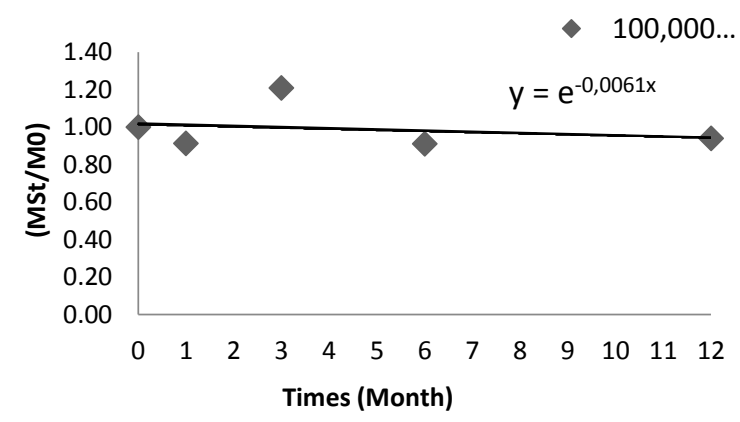

Fig. 12. Trends of strength loss for 1-year duration.

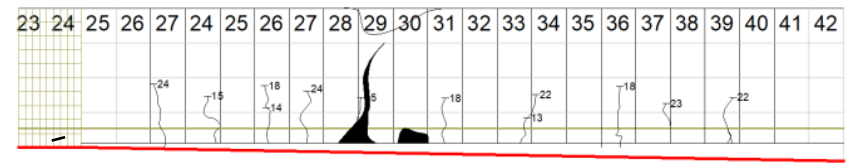

Fig. 13. Typical Failure due to fatigue loads on BF 100,000 cycles (BF12).

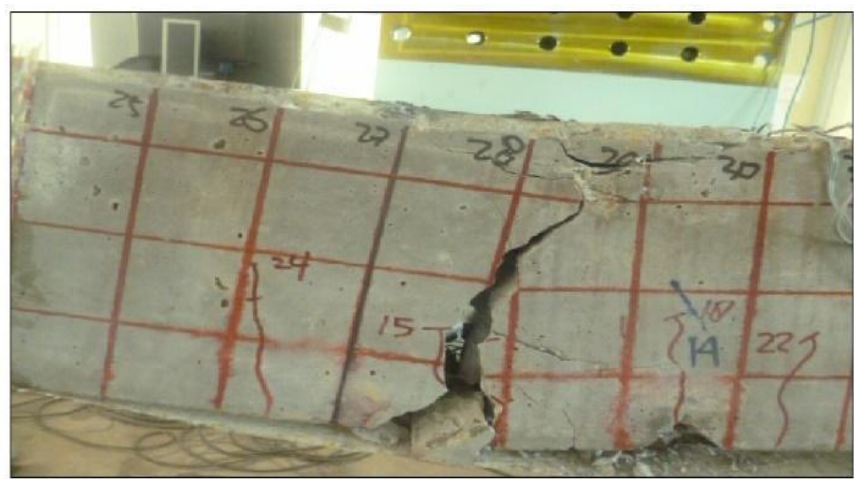

Fig. 14. Typical Failure due to fatigue loading on BF

\section{CONCLUSION}

There is a tendency of increasing deflection due to seawater immersion and fatigue load on the one-month immersed beam (BF1), three months immersed beam (BF3), six months immersed beam (BF6) and one-year immersed beam (BF12) towards immersed beam (BF0). This is indicated by the weakening of GFRP-S reinforcement capacity due to seawater immersion and fatigue load. There is a significant influence on the increase of strain on the concrete compressive capacity as well as the increase of strain on reinforcing steel due to fatigue loading and sea water immersion. An indication of the weakness of the structure due to fatigue and sea water immersion is indicated by the weakening of the bonding between the concrete surface and the GFRP sheet where the composite action of the GFRP sheet is weakened as the number of cycles increases, indicated by the debonding mechanism occurring in the GFRP during ruptures. The GFRP-S bending moment capacity to the concrete skin has decreased in 12 months by $2.38 \%$.

\section{REFERENCES}

[1] M. Elkenel, J.J. Myers, "Fatigue Performance of CFRP Strengthened RC Beams Under Environmental Conditioning and Sustained Load". J. of Composites for Construction (ASCE), vol. 13, no. 2, pp. 93-102, 2009.

[2] M. Sobhy, K. Soudki, and T. Topper, "CFRP-Strengthened and Corroded RC Beams Under Monotonic and Fatigue Loads", J. of Composites for Construction (ASCE), vol. 5, no. 4.pp. 0228-0236, 2002.

[3] X. Y. Sun, J. G. Dai, H. L. Wang, dan C. Xu, "Static and Fatigue Behaviour of CFRP-Strengthened RC Bridge Girders Subjected to Vehicle Overloading”, Adv. Steel Construction, vol. 11, No. 3, pp. 359371, 2015.

[4] ACI Committee, ACI 440.2R-08: Guide for the Design and Construction of Externally Bonded FRP System for Strengthening Concrete Structures, USA: Farmington Hills, 2008.

[5] K. Parikh, C. D. Modhera, "Application of GFRP on preloaded retrofitted beam for enhancement in flexural strength", Int. J. of Civil and Structural Eng., vol. 2, no. 4, pp. 1070-1080, 2012.

[6] L. Lam, Q. Hussain, P. Joyklad, and A. Pimanmas, "Behaviour of RC Deep Beams Strengthened in Shear using Glass Fiber Reinforced Polymer with Mechanical Anchors", International Conference on Environment and Civil Engineering, Pattaya, Thailand, 2015.

[7] C. G. Papakonstantinou, M. F. Petrou, and K. A. Harries, Fatigue "Behavior of RC Beams Strengthened with GFRP Sheets", Journal of Composites for Construction (ASCE), vol. 5, No 4, pp. 246-252, 2001. 
[8] V.A. Volnyy., and C.P. Pantelides, "Bond Length of CFRP Composite Attached to Precast Concrete Walls", Journal of Composites for Construction (ASCE), Vol. 3, No. 4, pp. 168-176, 1999.

[9] L. Song, \& Y. Zhiwu, "Fatigue Flexural Behaviour of Corroded RC Beams Strengthened with CFRP Sheets", Indian J. of Eng. \& Material Sci., 22, February pp. 77-84, 2015.

[10] A. B. Richard, and Geoffrey, C. Mays, "Fatigue Performance of Concrete Beams Strengthened with CFRP Plates", J. of Composites for Construction (ASCE), vol. 3. No. 2, Paper No. 18334, 1999.

[11] ACI Commite 318, "Building code requirement for structural concrete; American concrete institute, pp. 96-101, 1999. 